\title{
Experimental Study on Anti-splitting Tensile Properties of the Chopped Basalt Fiber Reinforced Concrete
}

\author{
Shengji Jin ${ }^{1, a}$, Xin Zhang ${ }^{2, b}$, Jian Zhang ${ }^{3, c}$ Xinpu Shen ${ }^{4, d}$ \\ ${ }^{1,2,3}$ School of Architecture \& Civil Engineering, Shenyang University of Technology, China
No.111, Shenliao West Road, Economic \& Technological Development Zone, Shenyang,110870, P.R. China

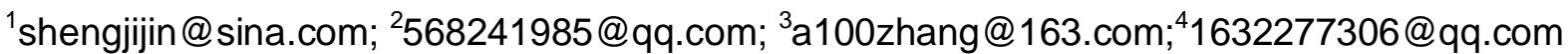

Key words: basalt fiber reinforced concrete, experimental study, basic mechanical properties, fiber content, pretreatment method

\begin{abstract}
In order to study the basic mechanical properties of chopped basalt fiber reinforced concrete (BFRC) and the impact of basalt fiber reinforced concrete by fiber content Experiments are conducted to examine the splitting tensile strength of this new composite construction material at different fiber volume fractions. The results showed that: The addition of fiber to concrete is at six different levels of volume fractions, namely $0.05 \%, 0.1 \%, 0.15 \%, 0.2 \%, 0.25 \%$ and $0.3 \%$, can decrease the slump of concrete and increase the splitting tensile strength in varying degree. Moreover, the degree of improvement is positively correlated with volume fraction of CBF. When direct mixing method and pretreatment method are compared while holding other conditions constant, it is found that BFRC produced by pretreatment method demonstrates better strengthening and toughening effects than direct mixing method. Conclusion: with the research findings presented above, this paper concludes that BFRC has favorable mechanical properties, however, fiber volume fraction as well as production method will affect its performance on splitting tensile strength in different extent.
\end{abstract}

\section{Introduction}

With the developments of recent technology, fiber reinforced concrete composite materials have applied widely in civil engineering field. However, a variety of fibers available in the market has its shortcomings. For example, the nature of carbon fiber is more stable, but the price is relatively expensive; the steel fiber has certain advantages in prices, but weak in corrosion resistance. As a new material, basalt fiber with its excellent mechanical properties is highly valued. $\mathrm{CBF}$, taking a natural volcanic rock as the only raw material, is environmental--friendly green fibers in the entire production process. The basic process of the production is that after crushing the rock in the furnaces and then melting in the high temperature of $1450 \sim 1500{ }^{\circ} \mathrm{C}$, finally formed with the use of platinum-rhodium alloy plate drawing drain quickly after pulling the nozzle plate ${ }^{[1]}$. Basalt fiber together with concrete which contains silicate as the basic ingredient has a natural good compatibility and dispersion. The character of basalt fiber material decides that it has good acid and other chemical properties, while its price is only $10 \%$ of the carbon fiber ${ }^{[2-4]}$. In 2002 the basalt fibers are included in the national 863 plan and to build a research and development base of basalt. Therefore, having carried out the study of the mechanical properties of basalt fiber reinforced concrete in terms of its application in the field of engineering is far-reaching, and become the current hot topic in the field of research ${ }^{[5-7]}$. Aiming at anti-splitting tensile performance test study of different content of fiber basalt reinforced concrete, we can determine the effect of fiber content on the basic mechanics of concrete, and then explore the reasonable content of basalt fiber reinforced concrete. 


\section{Organization of the Text}

\section{Test preparation}

\section{The experimental materials}

Splitting strength test uses the cube specimen of $150 \mathrm{~mm} \times 150 \mathrm{~mm} \times 150 \mathrm{~mm}$ and slag cement of PSA32.5; the fine aggregate applies natural river sand of 2.68fineness modulus while coarse aggregate takes ordinary gravel whose particle size is $5 \sim 31 \mathrm{~mm}$. Its fiber using chopped CBF, the density is $2650 \mathrm{Kg} / \mathrm{m} 3$, the supplier is Fuxin Jinshi Ltd, in Liaoning province. The relevant physical specifications of $\mathrm{CBF}$ are shown in Table 1, CBF sample as shown in Figure 1:

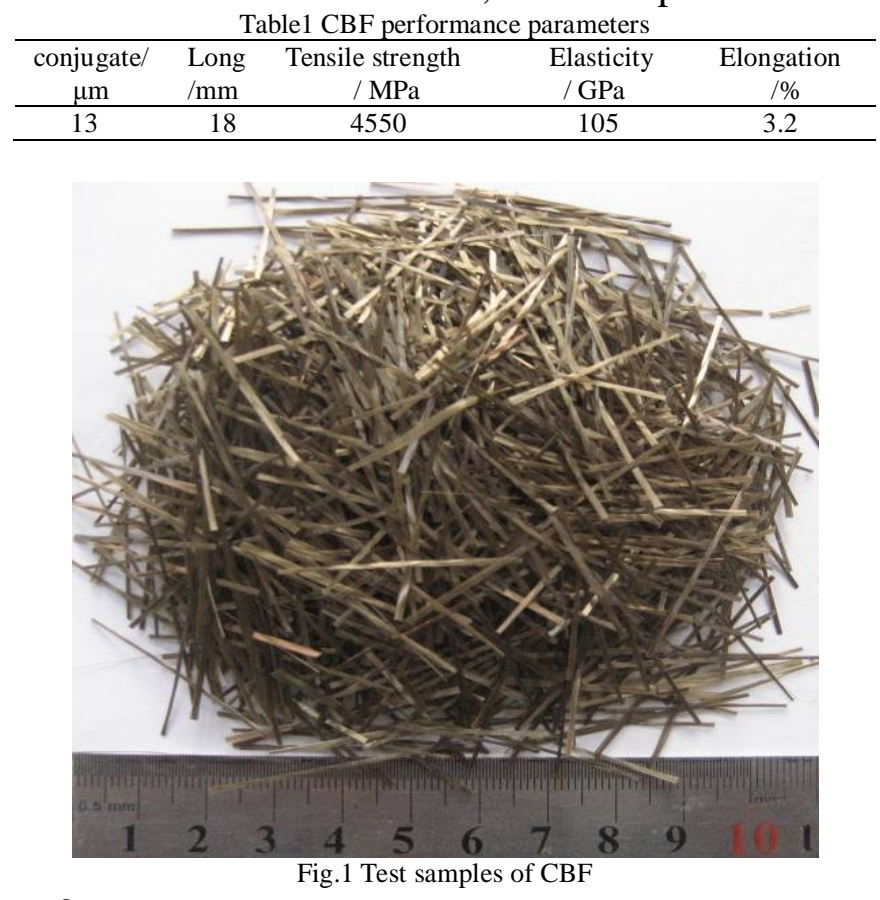

\section{Experiment design of concrete}

After checking a large number of references, and on the basis of several match test, and finally confirmed concrete mix design of C40 strength grade, as shown in Table 2.

\begin{tabular}{cccccc}
\multicolumn{7}{c}{ Table2 concrete mixture ratio } \\
\hline cement & sand & Stone & Water & Weight & $\begin{array}{c}\text { Water cement } \\
\text { ratio }\end{array}$ \\
\hline 450 & 670 & 1150 & 207 & 2477 & 0.46 \\
\hline
\end{tabular}

The volume content of CBF are $0.05 \%, 0.1 \%, 0.15 \%, 0.2 \%, 0.25 \%, 0.3 \%$ respectively, the concrete content of each component are shown in Table 3.

\begin{tabular}{ccccccc}
\multicolumn{7}{c}{ Table3 CBF concrete mixture ratio } \\
\hline number & cement & Water & Sand & stone & CBF \\
\hline BFRC1 & 450 & 207 & 670 & 1150 & 1.33 \\
BFRC2 & 450 & 207 & 670 & 1150 & 2.66 \\
BFRC3 & 450 & 207 & 670 & 1150 & 3.99 \\
BFRC4 & 450 & 207 & 670 & 1150 & 5.32 \\
BFRC5 & 450 & 207 & 670 & 1150 & 6.65 \\
BFRC6 & 450 & 207 & 670 & 1150 & 7.98 \\
\hline
\end{tabular}

\section{Test equipment}

Test mixer uses HY2-60 mixer, rated power is $10 \mathrm{KW}$ and current is 20A; Vibration table applies HZJ-I CNC magnetic vibration table, load vertical amplitude is $0.5 \mathrm{~mm}$, amplitude 
frequency is 2860 times / min; Conservation specimen box is SKYH-40B standard temperature and humidity conservation box, operating voltage is $220 \mathrm{~V}$, heating power is $500 \mathrm{~W}$, compressor power is $145 \mathrm{~W}$, temperature control $\geq 90{ }^{\circ} \mathrm{C}$, inside temperature difference $\leq 1{ }^{\circ} \mathrm{C}$. Split testing machine chooses YAW-1000 computer controlled servo pressure testing machine produced by Jinan Henry Gold Testing Machine Co, Ltd., including the host, servo oil source, control cabinet and computer, the maximum test force is $1000 \mathrm{KN}$, relative error is $\pm 1 \%$, the test machine as is shown in Figure 3 while the specimen mounting shown in Figure 4.

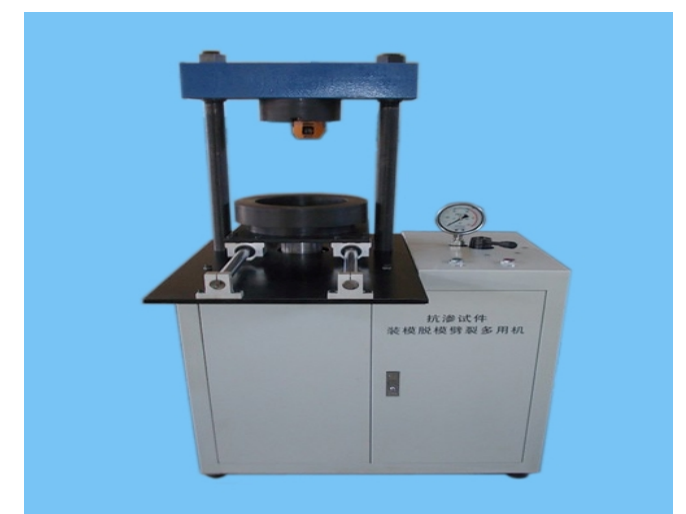

Fig.3 Splitting tensile test machine

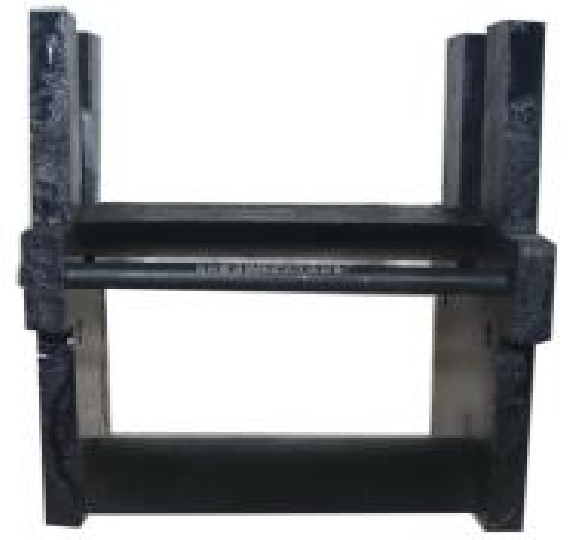

\section{Specimen manufacture and maintenance}

The test uses two preparation processes, namely the general incorporation (straight mixed method) and fiber pretreatment methods of incorporation (pretreatment), in order to ensure specimen quality and uniformity, we strictly control the various components of the material feeding sequence and mixing time, the two preparation processes are shown in Figure 2 and Figure 3 respectively: 


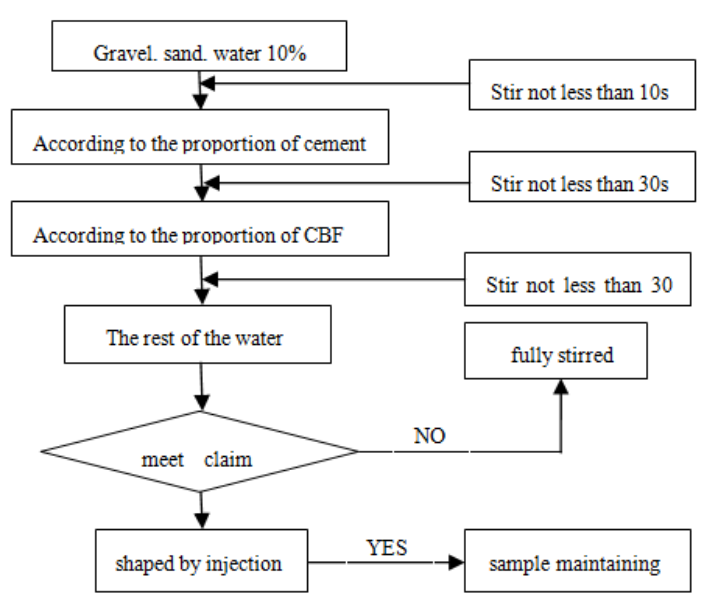

Fig. 2 production flow chart by direct mixing method

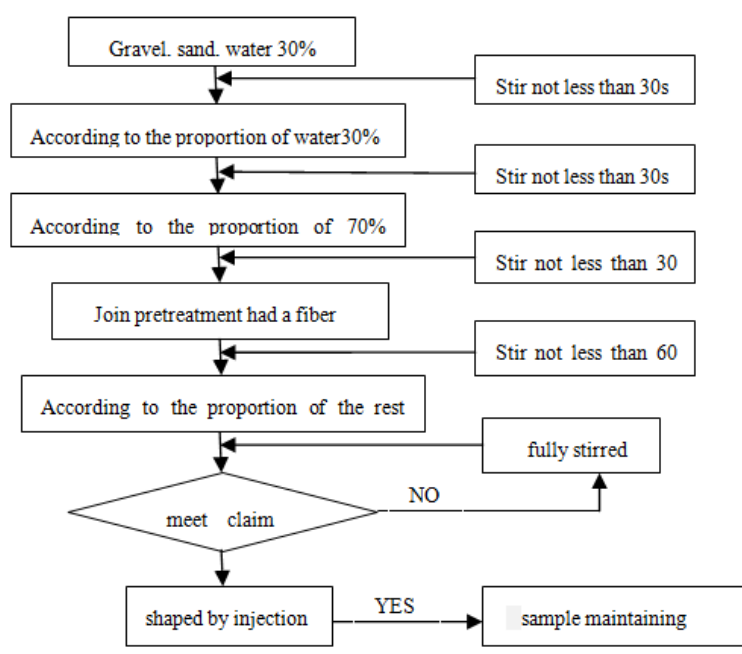

Fig. 3 production flow chart by fiber pretreatment method

The whole process of the test specimen completes in the control laboratory, the temperature is $23 \pm 5{ }^{\circ} \mathrm{C}$, humidity is more than $50 \%$. When the specimen formed, we should place it in the room in one or two days, and then removed after the specimen record number and remove the test mode, then quickly put the specimen in the room in which the temperature is $20 \pm 2{ }^{\circ} \mathrm{C}$, relative humidity is greater than $95 \%$ the curing time period of specimen is 28 days.

\section{experimental method}

Chopped basalt fiber reinforced concrete splitting strength test with reference to the current standard of the ordinary concrete mechanics performance test method standard (GB/T50081-2002), the specimen using the side length is $100 \mathrm{~mm}$ cube specimen, each group of three.

\section{The test results and analysis}

\section{Structural performance testing}

Test preparation of basalt fiber reinforced concrete slump test and observed its adhesiveness and water retention performance evaluation work Main reference test method of the steel fiber reinforced concrete (CECS13:89), and the common concrete mixture performance test method standard "(GB/T 50080-50080) provided by the method of test, slump test results are shown in table 4 , table 5 . 
Table4 Direct mixing of concrete slump

\begin{tabular}{ccccc}
\hline $\begin{array}{c}\text { Specimens } \\
\text { number }\end{array}$ & IPC & IBFRC1 & IBFRC2 & IBFRC3 \\
\hline slump (mm) & 48 & 46 & 43 & 42 \\
\hline $\begin{array}{c}\text { Specimens } \\
\text { number }\end{array}$ & IBFRC4 & IBFRC5 & IBFRC6 & \\
\hline slump ( mm) & 39 & 35 & 34 & \\
\hline \multicolumn{5}{c}{ Table5 The pretreatment method of concrete slump } \\
\hline $\begin{array}{ccccc}\text { Specimens } \\
\text { number }\end{array}$ & IIPC & IIBFRC1 & IIBFRC2 & IIBFRC3 \\
\hline slump (mm) & 48 & 48 & 45 & 43 \\
\hline $\begin{array}{c}\text { Specimens } \\
\text { number }\end{array}$ & IIBFRC4 & IIBFRC5 & IIBFRC6 & \\
\hline slump (mm) & 42 & 37 & 35 & \\
\hline
\end{tabular}

Relationship between slump and fiber volume content as shown in figure 4 .

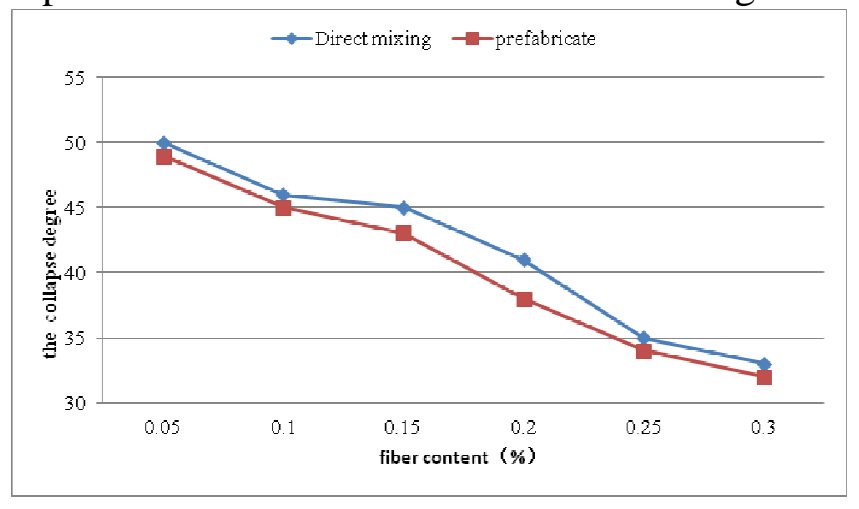

Fig.4 Relationship between Slump and fiber volume content

From Table 4 and Table 5, we know that the range of concrete slump is between $30 \mathrm{~mm}-50 \mathrm{~mm}$, to meet the requirements of "concrete quality control standards". As can be seen from Figure 4, when the concrete reference mix reaches the same level, the more the basalt fiber increases, the more the concrete slump decreases, under the same conditions, the slump of incorporation of fiber pretreatment method is slightly smaller than straight-doped concrete method. The reason is, first and foremost the right amount of fiber incorporation of concrete, due to the fiber and concrete bonding effect, they form a whole part of an interaction and form a three-dimensional disorder support system inside the concrete. When testing slump, separated trend is generated between the components of concrete, just because disorder support system inside the basalt fibers of concrete exists, to some extent, prevent the development of this trend; The second is when the concrete incorporating basalt fiber, its grout in conjunction with a portion of the fiber used to wrap the fibers, resulting in the original package for coarse and fine aggregate decrease, and with fiber content increase, the need of water slurry is gradually increasing, and finally the slump of concrete decreases with volume increase. In addition a large specific surface area of the fibers, the concrete internal friction increases, and this is one of the causes of the slump of the concrete reduced. Due to the addition of fiber, which suppress the fresh concrete bleeding and segregation, which in turn make concrete mixture exhibit a good cohesion, water retention, and then make the physical properties of concrete improved.

\section{Splitting test results and analysis}

The calculation formula of the splitting tensile strength of concrete cube is:

$$
f_{t s}=2 F / \pi A=0.637 F / A
$$

Among them, $\mathrm{f}_{\mathrm{ts}}$ is the splitting tensile strength of concrete cube (MPa), $\mathrm{F}$ is the sample destruction load $(\mathrm{N}), \mathrm{A}$ is the specimen bearing area $(\mathrm{mm} 2)$. This test uses the specimens produced by common mixture method and pretreatment method. The split test data are shown in Table 6 and Table 7. 
Table6 Splitting tensile strength and the rate of increase of BFRC by common mixture method

\begin{tabular}{ccccc}
\hline $\begin{array}{c}\text { Specimens } \\
\text { number }\end{array}$ & $\begin{array}{c}\text { CBF the } \\
\text { volume of } \\
\text { fraction(\%) }\end{array}$ & $\begin{array}{c}\text { split tensile } \\
\text { strength }\end{array}$ & relative & $\begin{array}{c}\text { strength } \\
\text { increasing } \\
\text { ratio(\%) }\end{array}$ \\
\hline IPC & 0 & 4.03 & 1 & - \\
IBFRC1 & 0.05 & 4.17 & 1.03 & 3.47 \\
IBFRC2 & 0.10 & 4.35 & 1.08 & 7.94 \\
IBFRC3 & 0.15 & 4.52 & 1.12 & 12.16 \\
IBFRC4 & 0.20 & 4.74 & 1.17 & 17.62 \\
IBFRC5 & 0.25 & 4.87 & 1.21 & 20.84 \\
IBFRC6 & 0.30 & 5.07 & 1.26 & 25.81 \\
\hline
\end{tabular}

Table7 Splitting tensile strength and the rate of increase of BFRC by fiber pretreatment mixture method

\begin{tabular}{ccccc}
\hline $\begin{array}{c}\text { Specimens } \\
\text { number }\end{array}$ & $\begin{array}{c}\text { CBF the } \\
\text { volume of } \\
\text { fraction(\%) }\end{array}$ & $\begin{array}{c}\text { split tensile } \\
\text { strength }\end{array}$ & relative & $\begin{array}{c}\text { strength } \\
\text { increasing } \\
\text { ratio(\%) }\end{array}$ \\
\hline IIPC & 0 & 4.03 & 1 & - \\
IIBFRC1 & 0.05 & 4.24 & 1.05 & 5.21 \\
IIBFRC2 & 0.10 & 4.47 & 1.11 & 10.92 \\
IIBFRC3 & 0.15 & 4.71 & 1.17 & 16.87 \\
IIBFRC4 & 0.20 & 4.84 & 1.2 & 20.1 \\
IIBFRC5 & 0.25 & 4.99 & 1.24 & 23.82 \\
IIBFRC6 & 0.30 & 5.12 & 1.27 & 27.05
\end{tabular}

Relationship between BFRC splitting tensile strength and fiber volume is shown in Figure 5.

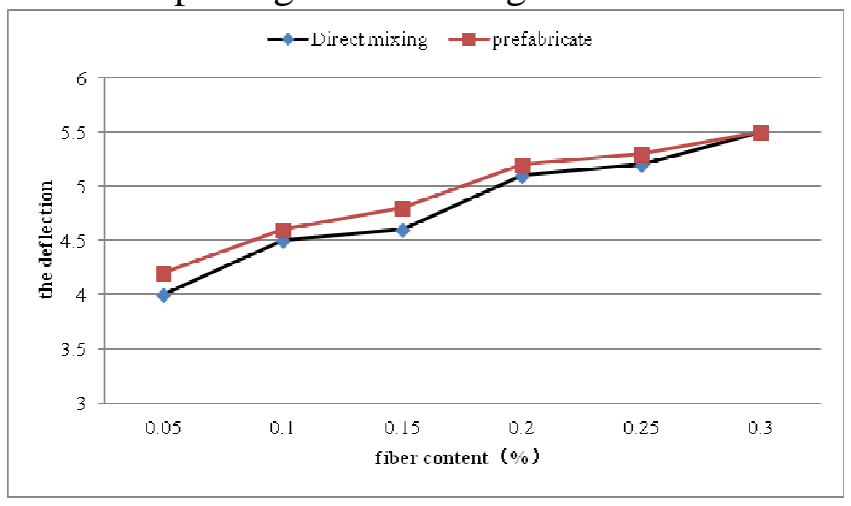

Fig.5 Relationship between splitting tensile strength and fiber volume content

As can be seen from the above data, due to the incorporation of concrete $\mathrm{CBF}$, two methods of incorporation of concrete splitting tensile strength are improved effectively, and with the increase of fiber content, the splitting tensile strength is growing, two methods of incorporation of fiber concrete showed the same trend, when the fiber content is $0.30 \%$, the splitting strength of two BFRC specimen have reached the maximum, this time straight mixed concrete method of splitting strength reaches $5.07 \mathrm{MPa}$, which increased $25.81 \%$ than the reference concrete splitting strength. The splitting strength of pre-prepared concrete reaches $5.12 \mathrm{MPa}$, which increased $27.05 \%$ than the splitting strength of straight mixed concrete method.

The test were the damage form of specimens is shown in figure 6 . 


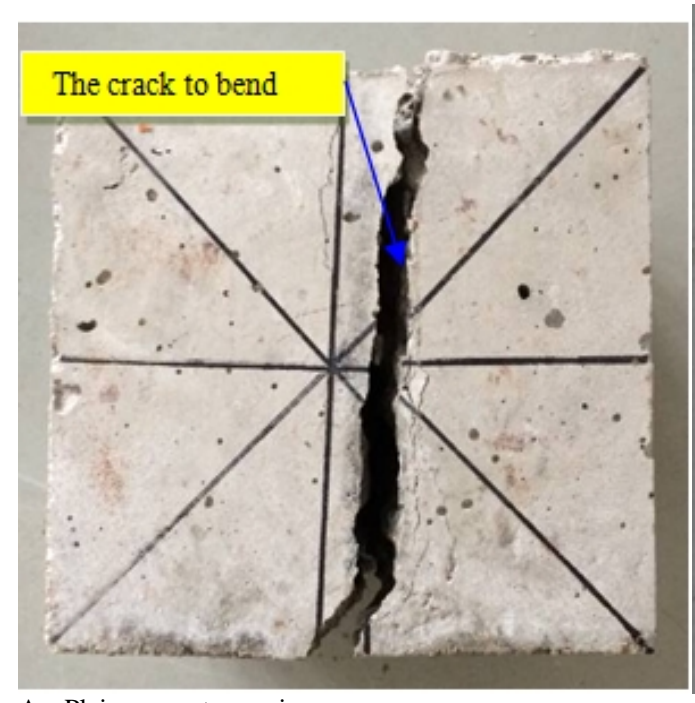

A Plain concrete specimen

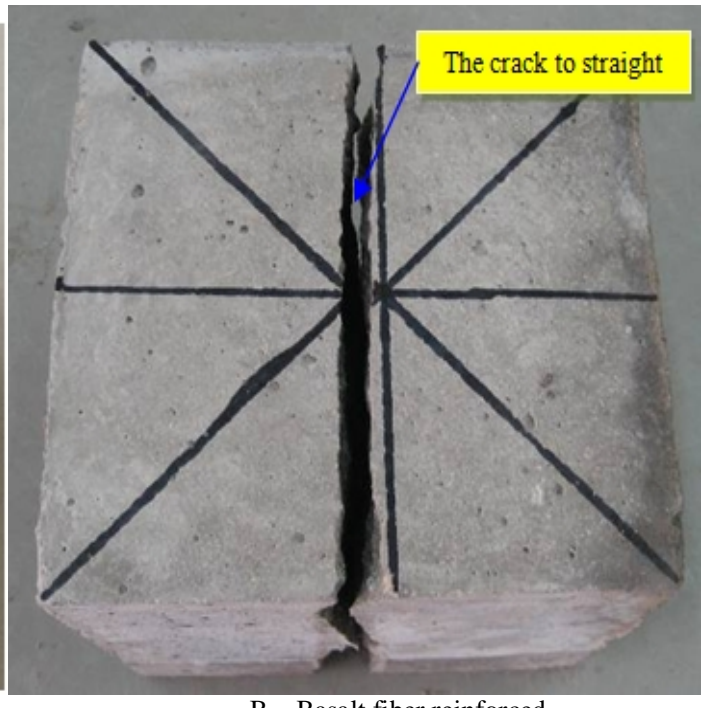

B Basalt fiber reinforced concrete specimens

Fig.6 The splitting tensile specimen damage form

By observing the specimen surface morphology and the development of crack can be seen: before the reference concrete specimen damage, there is hardly any damage signs within the splitting section (specimen carved lines), but also do not produce tiny cracks, specimen quickly split into two halves, the specimen shows the typical characteristics of brittle failure. Before the BFRC specimen damage, first appeared a series of tiny cracks in the carved line of the specimen, then crack development until it is split in half, which showed some toughness characteristics. Under the same conditions, the failure modes of straight mixed concrete method and pretreatment methods remained the same.

For reference concrete specimens, under the action of splitting tensile, internal specimens will produce tensile stress, with the increasing load, tensile stress increases, resulting in the rapid destruction of the specimen. On the one hand, this phenomenon partly because concrete is a brittle material, that can bear pressure and is impatient in pull. the splitting tensile strength produced by internal tensile stress shared by the condensation of materials, so soon quickly failed and result in destruction; on the other hand, the stress of the test specimen concentrated in the specimen central location, where it is difficult to transfer the tensile stress to the other part, thus accelerating the destruction of specimens and reflecting the characteristics of brittle failure. After Adding a certain amount of CBF into the reference concrete, the adsorption bond strength of interface between aggregate and mortar can be improved, at the same time, the fibers can form a three-dimensional disorder support system within the concrete. Due to the fiber itself has a relatively high modulus of elasticity, when the specimen is effected by splitting tensile, they can share much of the tensile stress, while these fibers can make the direction of internal tensile stress of concrete dispersed, which eased the stress concentration in the middle of the specimen to a large extent, and three-dimensional system supported by the

internal chaos can change the extension path of crack, thus can achieve reinforced and toughening effect and reflect the characteristics of a certain ductile failure. Since the pretreatment method in concrete fibers have a better bonding effect, so the effect of enhancing and toughness are better.

\section{Conclusions}

This essay thoroughly analyzed anti-splitting tensile mechanical properties of CBF reinforced concrete in different fiber content produced by two different preparation processes. Through the comparative analysis of the test results, we get the following conclusions:

(1) After the incorporation of CBF, slump and workability of concrete are subject to different 
degrees of impact, which has a direct relationship with the internal structure of the concrete, and thus affect the mechanical properties of the material.

(2) CBF has a strong effect on improving the splitting tensile strength of concrete, with the volume of content of CBF increases, the splitting tensile strength concrete enhances, the volume of content in the range of six tests, the maximum extent is $27.05 \%$.

(3) Preparation processes and methods have a direct impact on the performance of basalt fiber reinforced concrete. Under the same condition, BFRC produced by the fiber pretreatment methods of.

\section{Acknowledgment}

This research is a natural science fund subsidy project ( No.2015020583) and Project of Department of education of Liaoning Province (No. LJQ2013016)

\section{References}

[1] Tabatabaei Z S, Volz J S, Gliha B P, et al. Development of Long Carbon Fiber-Reinforced Concrete for Dynamic Strengthening[J]. Journal of Materials in Civil Engineering, 2014, 25(10):1446-1455.

[2] Zelinka S L, Rammer D R. Environmental Degradation of Fiber-Reinforced Polymer Fasteners in Wood[J]. Journal of Materials in Civil Engineering, 2014, 25(5):627-631.

[3] Ludovico M D, Prota A, Manfredi G. Structural Upgrade Using Basalt Fibers for Concrete Confinement[J]. Journal of Composites for Construction, 2012, 14(5):541-552.

[4] Borhan T M. Properties of glass concrete reinforced with short basalt fibre[J]. Materials \& Design, 2012(42):265-271.

[5] Sim J, Park C, Moon D Y. Characteristics of basalt fiber as a strengthening material for concrete structures[J]. Composites Part B Engineering, 2005, 36(6):504-512.

[6] Ma G, Li H, Wang J. Experimental Study of the Seismic Behavior of an Earthquake-Damaged Reinforced Concrete Frame Structure Retrofitted with Basalt Fiber-Reinforced Polymer[J]. Journal of Composites for Construction, 2013, 17.

[7] Yuan F, Pan J, Leung C K Y. Flexural Behaviors of ECC and Concrete/ECC Composite Beams Reinforced with Basalt Fiber-Reinforced Polymer[J]. Journal of Composites for Construction, 2013, 17(5):591-602. 